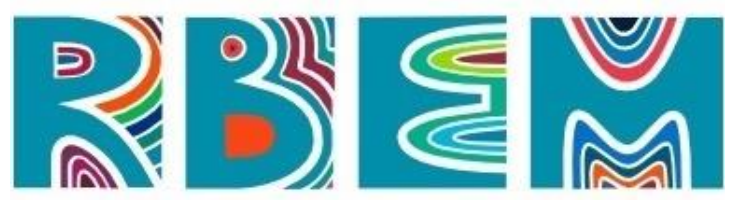

REVISTA BAIANA DE EDUCAÇÃO MATEMÁTICA

ARTIGO

do] https://doi.org/10.47207/rbem.v2i01.13139

\title{
Estágio Curricular Supervisionado em Matemática em Processo de Lesson Study on-line: adaptações, desafios e inovações
}

\author{
PINA NEVES, Regina da Silva \\ Universidade de Brasília (UnB). Pós-Doutorado. ORCID: https://orcid.org/0000-0002-7952-9665. E-mail: \\ reginapina@gmail.com.
}

BRAGA, Maria Dalvirene

Universidade de Brasília (UnB). Mestra. ORCID: https://orcid.org/0000-0003-0948-8228. E-mail:

dalvirenebraga@gmail.com.

FIORENTINI, Dario

Universidade Estadual de Campinas (UNICAMP). Pós-Doutorado. ORCID: https://orcid.org/0000-0001-55360781. E-mail: dariof@unicamp.br.

Resumo: No Brasil, o desenvolvimento da disciplina de Estágio Curricular Supervisionado em Matemática (ECSM) em processo de Lesson Study (LS) é recente e tem se revelado um momento privilegiado de aprendizagem profissional ao integrar professores orientadores, supervisores e futuros professores em ações reflexivas e colaborativas sobre o ensino de matemática nos anos finais do ensino fundamental e no ensino médio. Diante destas possibilidades, temos desenvolvido a disciplina de ECSM em processo de LS, em situações de ensino presencial, híbrido e remoto, no contexto da Licenciatura em Matemática, da Universidade de Brasília. Neste texto, discutimos aspectos de um segundo ciclo de LS, realizado no segundo semestre de 2020, com o objetivo de compreender as adaptações, os desafios e as inovações necessárias ao se desenvolver o ECSM em processo de LS online em situação de Ensino Remoto Emergencial (ERE), a partir dos elementos construídos em um LS presencial. Os dados construídos revelam os recursos tecnológicos inseridos, ao longo das etapas, e como eles possibilitaram a interação entre os participantes. Igualmente, revelam as adaptações necessárias para ampliar a participação dos estudantes no ERE e as experiências de docência dos estagiários. Assim, entendemos o LS on-line como possibilidade para contextos formativos atuais e futuros, de modo a minimizar distâncias geográficas, integrar professores orientadores e supervisores de diferentes escolas e universidades, ampliando a colaboração e o próprio desenvolvimento do LS enquanto processo de desenvolvimento profissional.

Palavras-chave: Lesson Study on-line. Ensino de Matemática. Ensino Médio.

\section{Supervised Curricular Internship in Mathematics in online Lesson Study Process: adaptations, challenges and innovation}

Abstract: In Brazil, the development of the subject of Supervised Curricular Internship in Mathematics (SCIM) in the Lesson Study (LS) process is recent and has proved to be a privileged moment of professional learning by integrating advisor professors, supervisors and pre-service teachers in reflective and collaborative actions on the teaching of mathematics in the final years of 


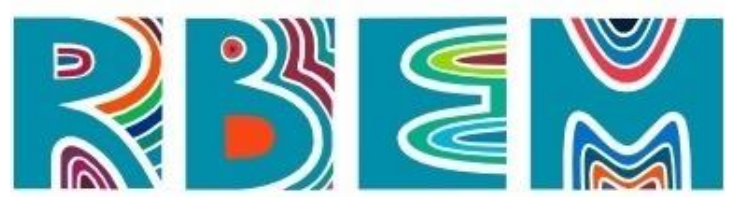

REVISTA BAIANA DE EDUCAÇÃO MATEMÁTICA

elementary and high school. Giving these possibilities, we have developed the subject of SCIM in LS process, in classroom, hybrid and remote teaching situations, in the context of Licentiate Degree in Mathematics, at the University of Brasilia. In this text, we discuss aspects of a second cycle of LS carried out in the second semester of 2020 in order to understand the adaptations, challenges and innovations necessary to establish the SCIM in an online LS process in an Emergency Remote Teaching (ERT) situation, from the elements built in a face-to-face LS. The constructed data show the technological resources inserted throughout the stages and how they enabled the interaction between the participants. Likewise, they show the necessary adaptations to increase the participation of students in the ERT and the teaching experiences of the interns. Thus, we understand the online LS as a possibility for current and future training contexts as a way of minimizing geographic distances, integrate advisor professors and supervisors from different schools and universities, expanding the collaboration and the establishment of LS as a process of professional development.

Keywords: Online Lesson Study. Teaching of Mathematics. High School.

\section{Pasantía curricular supervisada en matemáticas en el proceso de estudio de lecciones en línea: adaptaciones, desafíos e innovaciones}

Resumen: En Brasil, el desarrollo de la asignatura de Passantía Curriculares Supervisadas en Matemáticas (ECSM) en el proceso de Estudio de Lecciones (LS) es reciente y ha demostrado ser un momento privilegiado de aprendizaje profesional, ya que integra a profesores orientadores, supervisores y futuros profesores en reflexiones y acciones colaborativas en la enseñanza de las matemáticas en los últimos años de la escuela primaria y secundaria. En vista de estas posibilidades, hemos desarrollado la disciplina de ECSM en el proceso de LS, en situaciones de enseñanza presencial, híbrida y remota, en el contexto de la Licenciatura en Matemáticas, en la Universidad de Brasilia. En este texto, discutimos aspectos de un segundo ciclo de LS realizado en el segundo semestre de 2020, con el fin de comprender las adaptaciones, desafíos e innovaciones necesarias para desarrollar el ECSM en un proceso de LS en línea en una situación de Emergencia de Enseñanza Remota (ERE), a partir de los elementos construidos en un LS presencial. Los datos construidos revelan los recursos tecnológicos insertados a lo largo de las etapas y cómo permitieron la interacción entre los participantes. Asimismo, revelan las adaptaciones necesarias para ampliar la participación de los estudiantes en los ERE y las experiencias docentes de los pasantes. Así, entendemos la LS en línea como una posibilidad para los contextos formativos actuales y futuros con el fin de minimizar las distancias geográficas, integrar profesores y supervisores de diferentes escuelas y universidades, ampliando la colaboración y el propio desarrollo de la LS en línea.

Palavras-Clave: Estudio de Lecciones en línea. Enseñanza de Matemáticas. Escuela Secundaria.

\section{Introdução}

As Diretrizes Curriculares Nacionais (DCN) para a formação inicial em nível superior, estabelecidas pelo Conselho Nacional de Educação (CNE), regulam os debates nas instituições formativas que reverberam na reconstrução ou na manutenção dos Projetos Pedagógicos dos Cursos, frente à “[...] inércia das universidades quanto a repensar as licenciaturas" devido ao fato de que, historicamente, "dentro do modelo que inspira a universidade brasileira, a formação de professores ocupa um lugar bastante secundário" 


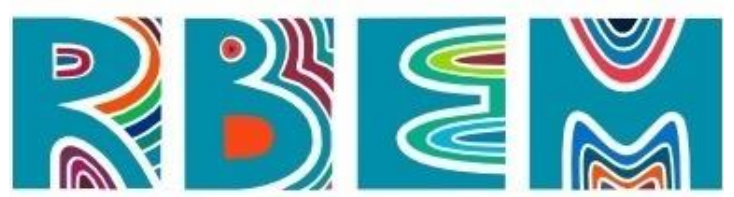

REVISTA BAIANA DE EDUCAÇÃO MATEMÁTICA

(LÜDKE, 1997, p. 6). Essas circunstâncias balizam os debates sobre a carga horária dos cursos, a curricularização da extensão, a prática como componente curricular, a necessidade de mais ou menos disciplinas de conteúdo matemático ou pedagógico e, de modo especial, o Estágio Curricular Supervisionado em Matemática (ECSM) e suas especificidades. Nesse contexto, a formação do(a) futuro(a) professor(a) de matemática e a almejada transformação dos cursos de licenciatura têm sido amplamente debatida pela Sociedade Brasileira de Educação Matemática (SBEM) junto a órgãos públicos e privados, sociedades científicas e a sociedade civil, auxiliando-nos na compreensão de que é preciso "romper a dicotomia entre o conhecimento matemático e o conhecimento pedagógico, a matemática da universidade e a matemática da escola (SOCIEDADE BRASILEIRA DE EDUCAÇÃO MATEMÁTICA, 2013, p.11-12).

Em paralelo a tudo isso, valiosos estudos produzidos no âmbito de programas de formação/pós-graduação, organizações e/ou grupos de pesquisa ${ }^{1}$ endossam esses debates, como, por exemplo, as contribuições advindas das revisões sistemáticas, realizadas, há mais de duas décadas, pelo Grupo de Estudo e Pesquisa sobre a Formação do Professor de Matemática (FIORENTINI et al., 2002; FIORENTINI; PASSOS; LIMA, 2016; GEPFPM, 2018) e colaboradores. Entre elas, destacam-se, de um lado, a compreensão de que formar o futuro(a) professor(a) de matemática, no Brasil, ainda, é extremamente desafiador, principalmente, por coexistir nos cursos diferentes crenças e concepções sobre o que é desejável para esta formação. Um desses aspectos é o fato de os formadores de professores e gestores se encontrarem em momentos diferenciados quanto à percepção, à análise e à intervenção frente ao Modelo 3+1 (GOMES, 2016), à tricotomia entre formação matemática, formação didático-pedagógica e prática profissional (FIORENTINI; OLIVEIRA, 2013) que resistem ao tempo. Isso gera, por sua vez, cursos amplamente teóricos (seja em conteúdos matemáticos, seja em conteúdos didático-pedagógicos) desvinculados, em grande parte, da escola, da sala de aula, dos estudantes e de suas necessidades. Por outro lado, amplia-se a constituição de comunidades de prática, de grupos colaborativos que (re)constrõem percursos formativos, tanto na formação inicial quanto na continuada, ao integrarem formadores de professores, professores, futuros professores e pesquisadores na produção de saberes, na reflexão sobre a prática docente e na socialização de experiências que

\footnotetext{
${ }^{1}$ Para mais informações acesse, por exemplo: http://www.sbembrasil.org.br/files/v_sipem/.
} 


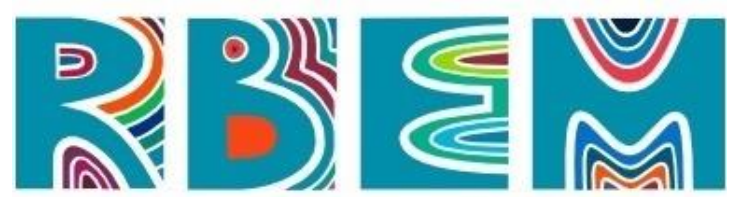

REVISTA BAIANA DE EDUCAÇÃO MATEMÁTICA

promovem desenvolvimento profissional, ao mesmo tempo em que (re)significam a própria relação universidade/escola (CRISTOVÃO; FIORENTINI, 2021).

Muitas dessas experiências têm sido desenvolvidas no ECSM, como discutem Barbosa e Lopes $(2018,2021)$ ao explicitarem ações, em diferentes instituições de ensino superior, que constituem o ECSM em oportunidade singular de significação dos conhecimentos e das experiências, vivenciadas pelo futuro professor (na educação básica e na universidade) a respeito da escola, da aula de aula, do ensino e da aprendizagem da matemática. O que é, também, vital na transição de futuro professor a professor, minimizando conflitos e dificuldades inerentes aos primeiros anos de atuação profissional (ZIMMER, 2017).

Nesse bojo, o Lesson Study $(L S)$, em função de sua natureza reflexiva e colaborativa, tem apresentado resultados promissores, promovendo entre os professores e futuros professores: a ampliação das habilidades de observar e mediar os processos de raciocínio dos estudantes; a importância do diálogo em sala de aula; a compreensão do papel da tarefa matemática na gestão da aula; a reflexão sobre as próprias práticas e suas influências para a aprendizagem matemática dos estudantes, entre outros (BAPTISTA et al., 2012; QUARESMA et al., 2014). A adoção do $L S$ na formação inicial, no Brasil, particularmente, no ECSM é recente e tem se revelado pertinente ao integrar professores orientadores, supervisores e futuros professores no desenvolvimento de ciclos de $L S$ nos anos finais do ensino fundamental e no ensino médio, constituindo-se em momento privilegiado de aprendizagem da docência e construção da identidade profissional (CRUZ; BITTAR, 2019; SILVA, 2020; PINA NEVES; FIORENTINI, 2021).

Diante dessas possibilidades, temos desenvolvido a disciplina de ECSM em processo de Lesson Study $(L S)$, em situações de ensino presencial, híbrido e remoto, no contexto da Licenciatura em Matemática, da Universidade de Brasília, onde a primeira e a segunda autoras deste texto atuam como formadoras de professores, em busca de respostas para os seguintes questionamentos: (1) Quais adaptações, desafios e inovações são necessários para o desenvolvimento do ECSM em processo de $L S$ presencial, híbrido ou on-line? (2) Quais aprendizagens e aprendizados são construídos por futuros professores ao participarem de um ECSM em processo de LS? (3) Quais aprendizagens e aprendizados são construídos por formadores de professores ao desenvolverem o ECSM em processo de $L S$ ? 


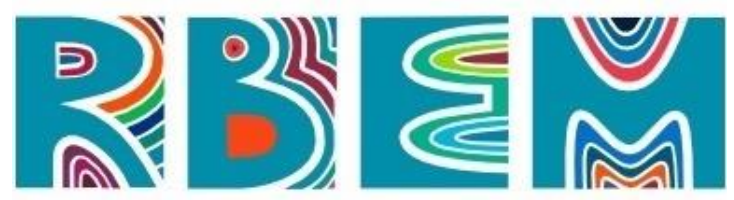

REVISTA BAIANA DE EDUCAÇÃO MATEMÁTICA

Neste artigo, optamos por discutir parte destes estudos, atentando-nos para o ECSM II - Ensino Médio, com o objetivo de compreender as adaptações, os desafios e as inovações realizadas no desenvolvimento de um processo Lesson Study ${ }^{2}$ on-line no segundo semestre de 2020. Em termos de organização textual, inicialmente, apresentamos algumas contribuições do $L S$, para, posteriormente, descrever nossa trajetória de aproximação ao $L S$ e sua adoção no ECSM. Em seguida, discutimos as etapas do ciclo de $L S$ on-line realizado, buscando elucidar as adaptações, os desafios e as inovações realizadas pelos participantes do ciclo.

\section{Lesson Study $(L S)$ : elementos centrais}

A literatura internacional e nacional tem socializado importantes experiências formativas em $L S$. Mais recentemente, a situação de ensino remoto, imposta pela pandemia de Covid-19, desafiou-nos a desenvolver $L S$ atentos às limitações e às possibilidades criadas pelo ensino remoto. Diante disso, neste item, optamos por reunir informações que nos auxiliaram nesse entendimento, especialmente, no $L S$ desenvolvido no âmbito deste estudo.

O $L S$ é um processo de desenvolvimento dos profissionais da educação, iniciado no Japão há mais de 150 anos. O termo Lesson Study (em inglês) ou Estudos de Aula (em Portugal) ou Pesquisa de Aula (denominado no Brasil, por BALDIN, 2009) origina-se do termo japonês jugyokenkyu (jugyo=aula, kenkyu=pesquisa). Ele integra pesquisadores, professores iniciantes e experientes, futuros professores e coordenação na concepção, no desenvolvimento e na avaliação de aulas, tendo como parâmetros centrais a participação ativa dos estudantes e suas aprendizagens (SOUZA; WROBEL; GAIGHER, 2017; BEZERRA, 2017).

Pesquisadores, como Lewis e Hurd (2011), ajudam-nos a compreender algumas características fundamentais do LS: Trabalho colaborativo: os professores trabalham colaborativamente para investigar a aprendizagem de seus alunos. São protagonistas do processo de produção do conhecimento e responsáveis pelo seu próprio aprendizado. Foco na

\footnotetext{
${ }^{2} \mathrm{O}$ estudo integra o projeto de pesquisa intitulado "Lesson Study e aprendizagem profissional docente de professores e futuros professores que ensinam matemática no Distrito Federal”, vinculado ao Programa de PósGraduação em Educação, linha de pesquisa Educação em Ciências, Matemática e Tecnologias, da Universidade de Campinas, ao Grupo de Investigação em Ensino de Matemática (GIEM), da Universidade de Brasília e, apoiado pela Fundação de Apoio à Pesquisa do Distrito Federal (FAPDF). O projeto integrou os estudos de pósdoutoramento realizados pela primeira autora sob a supervisão do terceiro autor.
} 


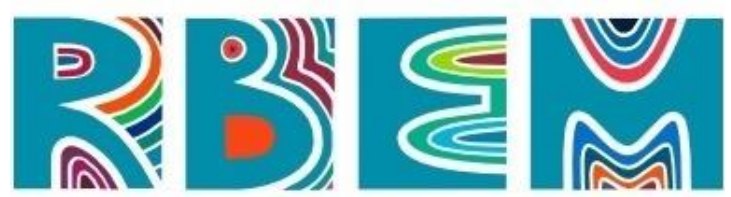

REVISTA BAIANA DE EDUCAÇÃO MATEMÁTICA

aprendizagem do aluno: o objetivo prioritário do $L S$ é proporcionar oportunidades de aprendizagem aos estudantes, por meio do estudo do currículo, do conteúdo, de pesquisas e de abordagens de ensino. O desenvolvimento profissional de professores é orientado pelas necessidades reais dos estudantes. Prática investigativa e reflexiva: o $L S$ proporciona a formação do professor que investiga sua própria prática, isto é, que planeja suas aulas de modo que elas sejam fonte de investigação, reflexão e produção de conhecimentos sobre o ensino e a aprendizagem.

Como sabemos, o $L S$ tem sido adotado em muitos países ocidentais; todavia, é de se registrar que, ao utilizá-lo em outro país, como é o caso do Brasil, questões culturais específicas demandam adaptações e exigem dos pesquisadores a capacidade de avaliação e tomada de decisão (LEWIS, 2016). Baldin e Felix (2011, p.6), por exemplo, registram como dificuldades "a postura individualista que prepondera na escola e na prática de sala de aula do professor que resiste em aceitar a presença de outros profissionais ou as interferências na aula". Todavia, aspetos positivos também têm sido revelados, em especial, suas possibilidades no que se refere ao fortalecimento do trabalho coletivo entre os professores e a possibilidade de produzir aulas que estimulem os estudantes. Nesse sentido, ampliam-se as expectativas entre os pesquisadores de que, no Brasil, o $L S$ potencialize as aprendizagens, diminuindo a

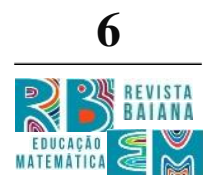
disparidade entre os que aprendem e os que não aprendem, gerando mais equidade.

Pesquisadores brasileiros têm estruturado estudos a fim de melhor compreender o $L S$, suas particularidades e possibilidades em nosso contexto educacional. Esses têm sido desenvolvidos, prioritariamente, na Região Sudeste e na formação continuada de professores, vinculados a instituições públicas e privadas. Mais recentemente, observam-se estudos em outras regiões e na formação inicial. Os resultados são promissores ao registrarem o $L S$ como importante elemento de promoção da cultura colaborativa por meio da realização do estudo, planejamento, execução, registro, análise e (re)planejamento de aulas (CURI, 2018; FIORENTINI et al., 2018; RICHIT; PONTE; TOMKELSKI, 2019; JÄHRING WANDERLEY; VEIGA FERREIRA DE SOUZA, 2020).

Tendo por base esses resultados, bem como o que trazem Darling-Hamond e Lieberman (2012), passamos a entender o LS como uma possibilidade para o desenvolvimento profissional do professor e/ou do futuro professor. Todavia, é importante registrar que o objetivo principal é proporcionar o desenvolvimento profissional que 


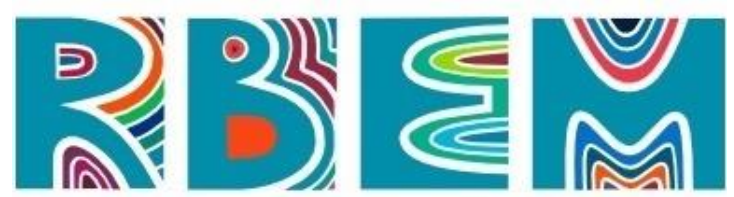

REVISTA BAIANA DE EDUCAÇÃO MATEMÁTICA

potencialize o aprofundamento do conhecimento dos estudantes, ou seja, melhorar a qualidade da aula e enriquecer as experiências de aprendizagem dos estudantes (DUDLEY, 2015).

Até 2019, grande parte desses estudos foi desenvolvida em situação de ensino presencial com professores, futuros professores e estudantes reunidos em salas de aula com observadores ao fundo e/ou nas laterais das salas; com plenárias integrando os participantes em análises críticas em busca de melhorias para as aulas. Muitas variações ocorriam em termos de estrutura física da escola, da sala de aula, o modo de organização das carteiras/mesas, a forma de organização dos estudantes em fileiras/grupos, a presença/ausência de recursos didático-tecnológicos nos espaços, entre outras. Todavia, a proximidade entre os participantes, a possibilidade de o professor regente transitar entre os estudantes, ouvi-los de perto, atendê-los em tempo real era viável para todos.

Nós vivenciamos isso ao desenvolvermos o ECSM em processo de $L S$ presencial, em diálogo com o Lesson Study Híbrido (LSH), construído no âmbito do Grupo de Sábado (GdS) (FIORENTINI et al., 2018; CRECCI; PAULA; FIORENTINI, 2019). Assim, tendo como referência o LSH, projetamos as seguintes etapas para nosso ciclo de LS: (1) Identificação do tema; (2) Estudo e planejamento; (3) Socialização do planejamento e simulação das aulas investigativas (plenária 1); (4) Desenvolvimento e observação das aulas investigativas; (5) Análise crítica das aulas desenvolvidas (Plenária 2); (6) Análise crítica das aulas desenvolvidas e replanejamento (Plenária 3) e (7) Sistematização da experiência.

Para desenvolver, no segundo semestre de 2019, este ciclo com 7 etapas, foram organizados de maneira autônoma cinco grupos de estagiários para atuarem em quatro escolas diferentes, a partir da vivência em quatro espaços de participação (grande grupo, grupo na universidade, grupo na escola, Drive/Whatsapp). Estes espaços possibilitaram a interação entre os futuros professores e entre estes e os professores orientadores e supervisores. Nesse contexto, buscou-se desenvolver: a escrita reflexiva da experiência pelos futuros professores; o estudo, o planejamento e a validação de planos de aulas de modo coletivo; o ensino exploratório (PONTE; BRANCO; QUARESMA, 2014) e a sistematização da experiência, realizada pelos futuros professores em parceria com as professoras orientadora e supervisora. Este ciclo evidenciou o potencial formativo do $L S$ presencial para a aprendizagem profissional do futuro professor que ensina matemática (PINA NEVES; FIORENTINI, 2021). 


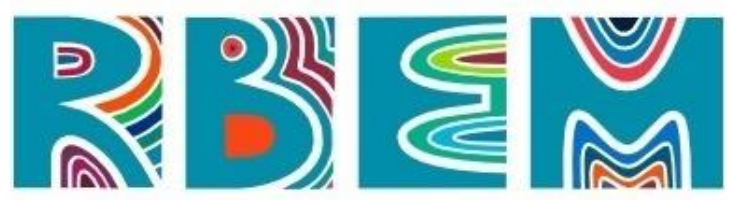

REVISTA BAIANA DE EDUCAÇÃO MATEMÁTICA

No ano de 2020, o distanciamento social, provocado pela Covid-19, impôs ao mundo o Ensino Remoto Emergencial (ERE) em larga escala. Essa situação desafiou os pesquisadores e professores, que já desenvolviam e/ou almejavam desenvolver $L S$, a buscarem outras estratégias/tecnologias para mantê-lo, modificá-lo, fortalecê-lo e ampliá-lo, constituindo, assim, em um importante e atual objeto de pesquisa.

De modo geral, a literatura têm apresentado algumas experiências de $L S$ on-line ${ }^{3}$ (desenvolvidos, inclusive antes da pandemia), que discutem os desafios de professores e futuros professores trabalharem de forma colaborativa, apesar de estarem separados pela distância (ANDREW, 2020). Para Martinez et al. (2020), nessas situações, é importante garantir que os participantes interajam de modo regular em espaços que favoreçam a aprendizagem colaborativa. Para tanto, se faz necessária a presença constante, acolhedora e provocativa do(s) responsável/responsáveis pelo $L S$, alternando atividades síncronas e assíncronas, com videogravações das diferentes etapas do processo e o compartilhamento destas para análises. Ademais, os pesquisadores registram a possibilidade de ter especialistas em algumas etapas do $L S$, haja vista a facilidade de unir pessoas, independente da distância que as separam.

Tudo isso revela a importância de se desenvolver Lesson Study on-line em diferentes contextos formativos, em diferentes países, de modo a ampliar a compreensão sobre eles. Este estudo busca contribuir com essa discussão na medida em que se propôs a compreender quais adaptações, desafios e inovações foram realizados no desenvolvimento do ECSM em processo de $L S$ on-line, a partir da experiência de um primeiro ciclo presencial.

\section{O ECSM em processo de Lesson Study on-line: adaptações, desafios e inovações}

Participaram do ciclo de LS on-line, realizado no segundo semestre de 2020, 15 estagiários, sendo cinco mulheres e 10 homens, com idades entre 21 e 26 anos, a maioria entre 21 e 23 anos. Todos já tinham cursando a disciplina de ECSM I, em situação de ensino presencial, tendo 11 deles integrado o ciclo de $L S$ presencial. Do mesmo modo que no ciclo presencial, os estagiários se organizaram de modo autônomo para a composição de cinco

\footnotetext{
${ }^{3}$ Entendemos o LS on-line como aquele no qual todas as etapas do LS ocorrem virtualmente.
} 


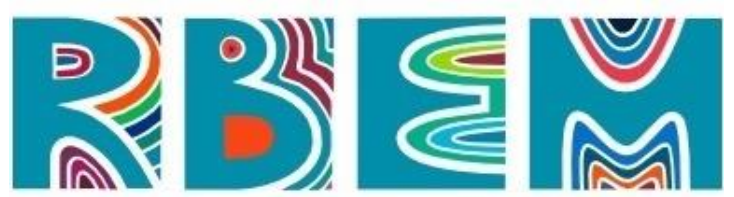

REVISTA BAIANA DE EDUCAÇÃO MATEMÁTICA

grupos, sendo quatro com três futuros professores e um com quatro futuros professores. Integraram, também, este ciclo, uma professora supervisora e duas professoras orientadoras.

Diferentemente do ciclo presencial, optamos por trabalhar em uma escola pública com uma professora supervisora, com ampla experiência no ensino médio, egressa do curso de especialização em Metodologias do Ensino de Matemática da UnB, professora-parceira em diversas ações extensionistas, com disponibilidade de tempo e interesse em integrar-se às ações do ECSM. Tal decisão pautou-se na hipótese de que o aumento do número de escolas e de professores supervisores ampliaria as dificuldades de gestão do ciclo, em especial, pelo fato de ser a primeira vez que o desenvolveríamos no formato on-line. Ademais, a presença de duas professoras orientadoras aconteceu em resposta à necessidade observada no ciclo presencial de integrar mais formadores de professores no processo de $L S$ em função da demanda dos grupos por atendimento e por estudos específicos, relativos aos tópicos curriculares da regência (PINA NEVES; FIORENTINI; SILVA, 2022, no prelo).

Assim, professoras orientadoras e supervisora passaram a realizar encontros virtuais para o planejamento, acompanhamento e avaliação do ECSM em processo de LS on-line. Nos encontros realizados via plataforma $Z_{o o m}{ }^{4}$, foi possível deliberar sobre a documentação exigida, o cronograma das observações das aulas da professora supervisora, as formas de interação entre esta e os estagiários, o acesso à plataforma adotada na Secretaria de Estado e Educação do Distrito Federal (SEEDF), bem como sobre o $L S$ e suas possibilidades para o ECSM, o atual currículo em fase de implantação na rede de ensino, o novo ensino médio em fase de execução em escolas piloto, entre outros aspectos.

O desenvolvimento da disciplina de ECSM contou com o espaço do Sistema Integrado de Gestão de Atividades (SIGAA) para a alocação de materiais, registro de frequência e notas; igualmente, contou com o Sistema Eletrônico de Informações (SEI) para a formalização da documentação do estágio junto à SEEDF. Já a rotina de interação entre estagiários e professoras orientadoras foi realizada via plataforma Zoom, por meio de encontros semanais síncronos, acrescidos de momentos assíncronos. O Google Drive constituiu-se em espaço de registro, escrita reflexiva e compartilhada das ações dos estagiários e das devolutivas das produções pelas professoras orientadoras. Além do mais, contamos com um grupo de

\footnotetext{
${ }^{4}$ A plataforma Zoom permite chamadas de videoconferência para diversos fins, desde reuniões familiares, com equipes de trabalhos e utilização na educação.
} 


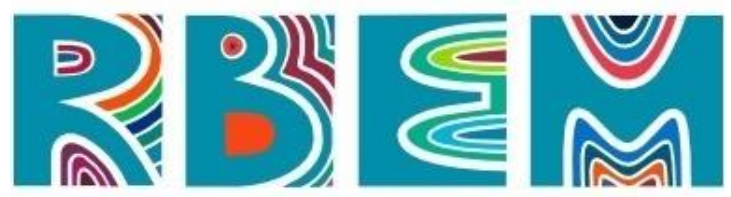

REVISTA BAIANA DE EDUCAÇÃo MATEMÁTICA

WhatsApp que proporcionou o contato rápido e a resolução imediata de questionamentos e/ou deliberações sobre a agenda e as ações.

O fato de no ERE os estagiários não frequentarem, presencialmente, a universidade e a escola, provocou mudanças aos espaços de participação. As adaptações ocorreram em relação aos recursos tecnológicos adotados e aos modos de interação entre os participantes, exigindo menor duração para os encontros síncronos, otimização do tempo de fala nesses encontros, entre outros aspectos. Tudo isso exigiu dos participantes adaptações, também, em seus locais de estudo, buscando melhorias quanto à: iluminação, acústica, qualidade do microfone e da conexão de internet. Temos ciência que nem sempre foi possível garantir qualidade e/ou a presença de notebooks e/ou celulares devido às limitações financeiras do grupo. O Quadro 1 abaixo reúne informações sobre os espaços de participação constituídos e os recursos utilizados em cada um deles.

Quadro 1: Espaços de participação constituídos

\begin{tabular}{|c|c|c|c|}
\hline $\begin{array}{l}\text { Espaços de } \\
\text { participação }\end{array}$ & $\begin{array}{l}\text { Recursos } \\
\text { tecnológicos }\end{array}$ & Participantes & Ações \\
\hline $\begin{array}{l}\text { Grande grupo } \\
\text { Sextas-feiras } \\
15 \text { encontros no } \\
\text { semestre (60 horas) }\end{array}$ & $\begin{array}{l}\text { 2h de modo } \\
\text { síncrono na } \\
\text { plataforma } \\
\text { Zoom } \\
+2 \mathrm{~h} \text { de modo } \\
\text { assíncrono usando } \\
\text { oDrive, o } \\
\text { Youtube }\end{array}$ & $\begin{array}{l}\text { Professora } \\
\text { orientadora e } \\
\text { futuros } \\
\text { professores }\end{array}$ & $\begin{array}{l}\text { Encaminhamentos administrativos, éticos e legais do estágio; } \\
\text { estudos sobre as orientações curriculares, o livro didático, a } \\
\text { Base Nacional Comum Curricular (BNCC); estudo, } \\
\text { planejamento e análise de aulas a partir das etapas do LS. } \\
\text { As } 2 \mathrm{~h} \text { assíncronas contou com a socialização de arquivos em } \\
\text { word e em pdf no Drive compartilhado e/ou por meio de vídeos } \\
\text { disponibilizadas em canais do YouTube }{ }^{5} \text {, como no canal do } \\
\text { Grupo de pesquisa Grupo de Investigação em Ensino de } \\
\text { Matemática da UnB (GIEM/UnB). }\end{array}$ \\
\hline Grupos & $\begin{array}{l}\text { Whatsapp } \\
\text { Meet }\end{array}$ & $\begin{array}{l}\text { Futuros } \\
\text { professores }\end{array}$ & $\begin{array}{l}\text { Conversas, comentários sobre as aulas observadas, sobre o } \\
\text { planejamento e o estudo; reclamação, indignação, } \\
\text { comemoração, entre outras ações. }\end{array}$ \\
\hline Drive & & $\begin{array}{l}\text { Professoras } \\
\text { orientadoras e } \\
\text { futuros } \\
\text { professores }\end{array}$ & $\begin{array}{l}\text { Socialização de documentos, artigos, planejamentos, análise } \\
\text { crítica das observações das aulas, escrita do relatório de estágio. }\end{array}$ \\
\hline Whatsapp & & $\begin{array}{l}\text { Professoras } \\
\text { orientadora e } \\
\text { supervisora e } \\
\text { futuros } \\
\text { professores }\end{array}$ & $\begin{array}{l}\text { Comunicação rápida para fins de organização de agendas, } \\
\text { horários, troca de imagens e de documentos que não exigiam } \\
\text { tanta edição. }\end{array}$ \\
\hline
\end{tabular}

Fonte: Relatório da pesquisa.

${ }^{5}$ É uma plataforma de compartilhamento de vídeos. 


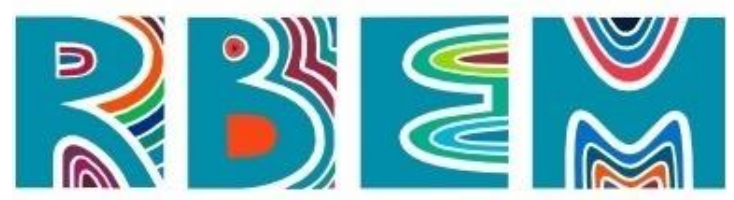

REVISTA BAIANA DE EDUCAÇÃO MATEMÁTICA

No espaço grande grupo, a professora orientadora organizou e mediou virtualmente a leitura de textos, a apresentação de seminários, a análise das aulas, o estudo dos documentos oficiais, as discussões sobre o ensino de matemática e a escrita do relatório de estágio. A bibliografia contemplou, igualmente, discussões atuais em relação à formação de professores, ao estágio supervisionado, à prática docente, ao ensino exploratório, ao Lesson Study, entre outros.

Enquanto no ciclo presencial, os grupos se reuniam na universidade, em salas de aula, laboratórios; no ciclo on-line, eles se reuniram remotamente. Todavia, o espaço continuou sendo gerido pelos futuros professores para a troca de informações, angústias e alegrias. $\mathrm{O}$ espaço grupos na escola foi alterado do presencial para o remoto, mantendo o acompanhamento das aulas da professora supervisora. Em alinhamento ao ciclo presencial, desenvolvemos as mesmas sete etapas do $L S$ adotado, em situação de ensino remoto, tanto na universidade quanto na escola, buscando compreender as necessidades dos participantes e como elas impactavam no desenvolvimento das etapas nos diferentes espaços de participação.

\section{Etapa 1: Identificação do tema}

Os futuros professores acompanharam a prática docente da professora supervisora, reunindo-se com ela em momentos pré-agendados e por meio da observação/colaboração em suas aulas síncronas e acessando os materiais disponibilizados na plataforma para as aulas assíncronas. Diferentemente do ciclo presencial, eles não tiveram a oportunidade de conhecer a estrutura física da escola, tendo contato com ela, somente, por meio dos relatos orais da professora supervisora e dos estudantes. Nessas condições, eles assistiram às aulas síncronas no Meet, às segundas-feiras, às $8 \mathrm{~h}$, e às quintas-feiras, às $8 \mathrm{~h} 50 \mathrm{~min}$. Acompanharam às terçasfeiras, das $14 \mathrm{~h} 00$ às 14h45min, o plantão de dúvidas, de modo assíncrono (com materiais postados no Classroom $^{6}$ ).

Acompanharam, também, alguns atendimentos síncronos, realizados pela professora supervisora aos estudantes de dependência. Além de acompanhar as aulas, os futuros

\footnotetext{
${ }^{6}$ Google Classroom é uma plataforma do Google Apps para área da educação, desenvolvido como um sistema de gerenciamento de conteúdo como recurso para instituições de ensino. Tem como proposta simplificar a criação, a distribuição e a avaliação de tarefas.
} 


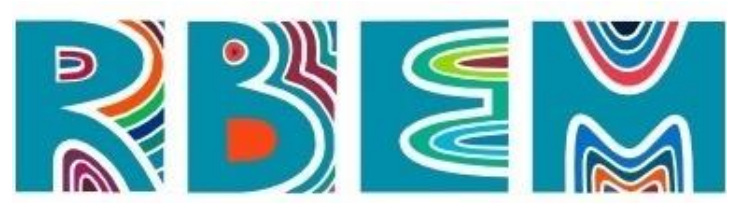

REVISTA BAIANA DE EDUCAÇÃO MATEMÁTICA

professores acessaram materiais e formulários avaliativos, disponibilizados no Classroom. A Figura 1 ilustra uma das aulas ministradas pela professora supervisora e observada pelos futuros professores.

Figura 1: Registro de uma aula síncrona na plataforma meet ministrada pela professora supervisora

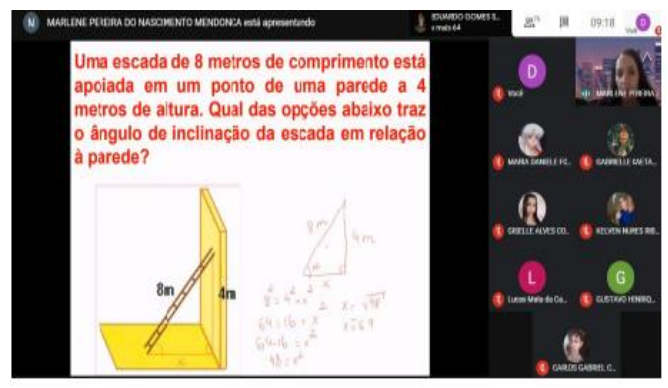

Fonte: Arquivo da pesquisa.

Tudo isso permitiu a constatação de que, dos 370 estudantes matriculados no segundo ano, 70 estudantes, em média, acompanhavam as aulas síncronas; destes somente seis estudantes participavam ativamente, esclarecendo dúvidas ou respondendo aos questionamentos no chat ou oralmente. Alguns acompanhavam as atividades pelo Classroom e outros acessavam as atividades em formato PDF, indo até à escola, semanalmente, para retirá-las. Essa experiência mostrou aos futuros professores a complexidade do ERE e o quanto ele demandava da equipe gestora da escola, no sentido de realizar a busca ativa pelos estudantes, o entendimento de suas realidades sociais, financeiras, tecnológicas e educacionais. Eles conheceram o trabalho da professora supervisora, sua atuação nas aulas síncronas e suas angústias face às ausências e à falta de participação dos estudantes. Além disso, perceberam a necessidade de atendimento individual pelo WhatsApp para os estudantes que não possuíam os recursos tecnológicos necessários para acessarem as aulas síncronas ou assíncronas.

Em meio a tudo isso, os tópicos curriculares da regência foram definidos de modo a contemplar, de um lado, o conteúdo programático do segundo ano e, de outro, as necessidades da professora supervisora de criar momentos de revisão de conteúdos anteriores, já ministrados por ela. Assim, foram definidos os seguintes tópicos curriculares: círculo e circunferência; triângulos isósceles, equilátero e escaleno; triângulo retângulo, teorema de Pitágoras; Relações Trigonométricas, Lei dos Senos e Lei dos Cossenos. A partir de então, os 


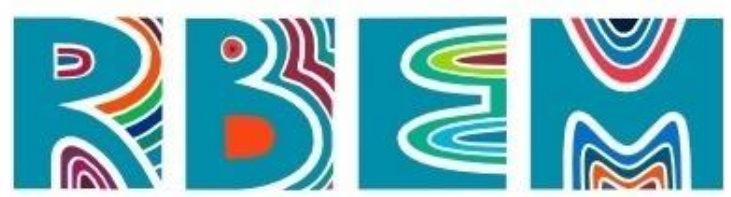

REVISTA BAIANA DE EDUCAÇÃO MATEMÁTICA

estagiários tiveram como desafios a serem considerados, na etapa 2: a ampliação da participação dos estudantes durante as aulas síncronas e assíncronas; as situações de abandono escolar diante das necessidades de trabalho, impostas pela pandemia; as dificuldades conceituais em tópicos curriculares atuais e anteriores; as diferenças de acesso ao conhecimento matemático entre aqueles que acompanhavam as aulas síncronas e assíncronas e aqueles que retiravam os materiais impressos na escola, devolvendo-os, posteriormente, para a correção da professora supervisora.

\section{Etapa 2: Estudo e Planejamento}

Diferentemente do ciclo presencial, os estagiários não tiveram a oportunidade de realizar os encontros nas instalações da universidade e buscaram minimizar tais incômodos criando mais oportunidades de diálogos ao longo da semana. Logo, os grupos se reuniam com o apoio de plataformas como Google Meet ou Teams, comunicando-se, também, por meio do grupo no Whatsapp, do qual a professora orientadora fazia parte, colaborando e acompanhando as ações.

A escolha dos recursos tecnológicos e a avaliação de sua pertinência, na ampliação da participação dos estudantes durante as aulas síncronas, ocupou lugar de destaque nessa fase. Assim, termos como mesa e caneta digitalizadoras, lousa digital, Meet, Classroom, Forms, Kahoot, Quiz, infográfico, entre outros se tornaram constantes nos diálogos e nos registros no Drive. As muitas opções foram apresentadas pelos estagiários com desenvoltura, criticidade, curiosidade, constituindo-se em momento de protagonismo e tomada de decisão dos futuros professores.

Do mesmo modo que no ciclo presencial, os futuros professores revelaram, em diversos momentos, o quanto esta etapa exigiu deles dedicação, estudo, debate, consulta aos documentos curriculares e aos artigos selecionados. Entretanto, observamos que o esclarecimento de dúvidas conceituais, a troca de resoluções e as deliberações quanto ao planejamento foram mais morosas no ciclo on-line, sendo necessários entre cinco e seis encontros para que o planejamento fosse construído. $\mathrm{O}$ fato de o planejamento ser discutido em várias instâncias (no grupo, no grande grupo, junto à professora supervisora) possibilitava 


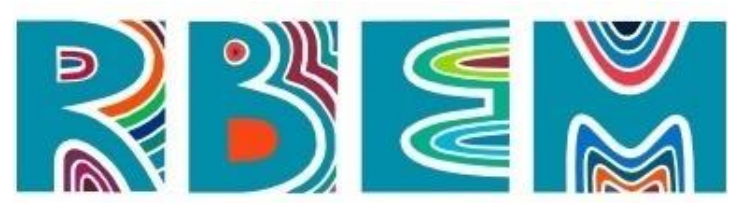

REVISTA BAIANA DE EDUCAÇĀO MATEMÁTICA

melhorias constantes, o que mostrava aos futuros professores seu valor enquanto ação profissional.

Gastamos muito tempo para fazer o plano, não foi fácil, mas, agora, vendo o resultado, valeu a pena. Estamos nos sentindo seguros para a regência (Estagiário, Grupo 1).

Ao ter essa experiência de preparar aulas aprendemos que o ensino engloba muitas coisas, além de só o mero ensinar. Temos que estar atentos não só aos conteúdos matemáticos, mas, como por meio dele o aluno vai aprender e ressignificar, para poder aplicar em seu cotidiano, e consequentemente ter uma aprendizagem significativa. (Estagiário, Grupo 2).

$\mathrm{O}$ artigo que mais nos fez questionar e analisar a forma como fomos ensinados e a forma como queremos ensinar foi: Exercícios, Problemas e Explorações: Perspectivas de professoras num estudo de aula (PONTE, et. $a l, 2015)$. Essa separação de tarefas e o que o professor pretende desenvolver com cada uma delas terá bastante utilidade na nossa carreira como futuros professores (Estagiário, Grupo 3).

O template, adotado no âmbito deste estudo, apresentava itens já conhecidos pelos estagiários da experiência do ciclo presencial e/ou de outras disciplinas do curso, como: participantes, conhecimento-alvo, objetivos, pré-requisitos, ano escolar, duração, material necessário e tarefa matemática. Entretanto, os itens que compõem o Quadro 2 foram bem desafiadores para eles, especialmente, "ações esperadas dos estudantes" pela falta de conhecimento dos modos de pensamento/registro matemático dos estudantes e pouca vivência com a escrita detalhada do planejamento.

Quadro 2: Parte do template de planejamento adotado

\begin{tabular}{|l|l|l|l|}
\hline Tempo & Ações dos professores & Ações esperadas dos estudantes & $\begin{array}{l}\text { Observações após do } \\
\text { desenvolvimento da aula }\end{array}$ \\
\hline & & & \\
\hline Reflexões & & & \\
\hline
\end{tabular}

Fonte: Arquivo pessoal das pesquisadoras.

\footnotetext{
${ }^{7} \mathrm{O}$ template de planejamento adotado neste estudo foi construído no âmbito do projeto "TIME - Teachers' Inquiry in Mathematics Education" https://time-project.eu/en. Sua utilização de forma traduzida e adaptada tem sido realizada em diálogo com Carl Winsløw, https://www.ind.ku.dk/winslow/winslow/.
} 


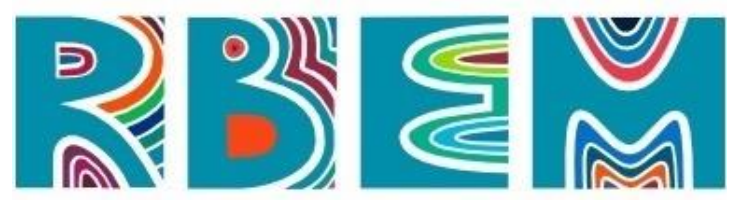

REVISTA BAIANA DE EDUCAÇÃO MATEMÁtICA

As várias versões do planejamento (Quadro 3) mostravam, igualmente, que a escrita era uma ação de alta complexidade para a maioria dos estagiários, exigindo retomadas, complementações e reescritas de modo a garantir que o planejamento fosse compreensível a todos.

Quadro 3: Elementos Iniciais da Primeira versão de um Plano de Aula

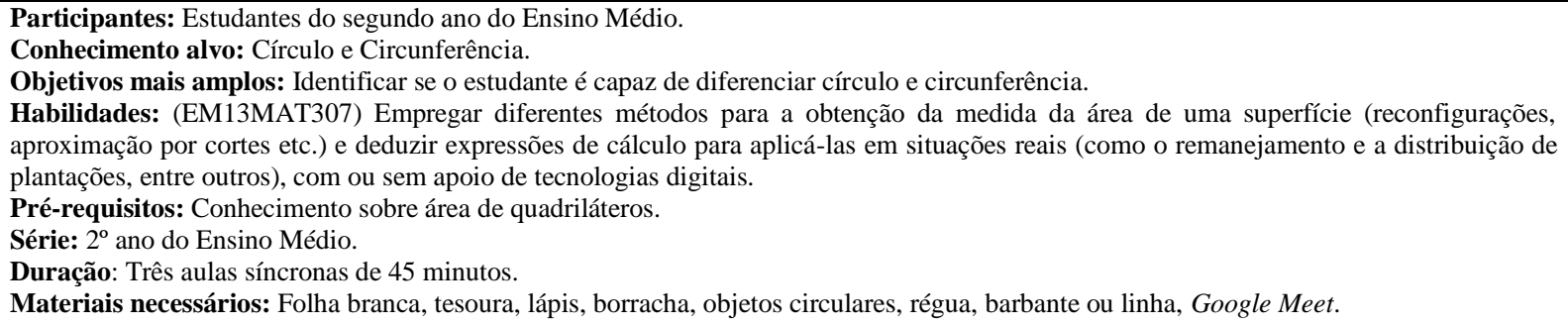

Fonte: Relatório final de Estágio do Grupo1.

Ao longo desta etapa, os futuros professores tiveram a oportunidade de discutirem suas propostas iniciais com as professoras orientadoras e supervisora e reverem a escrita do plano de aula. Como exemplo, tem-se a proposta inicial do Grupo 1, expressa no Quadro 3, foi revisitava várias vezes a partir de análises como: o objetivo como está escrito revela uma preocupação mais avaliativa. É o que vocês almejam? O objetivo "explorar e compreender a diferença entre circunferência e círculo (raio, diâmetro, corda, razão pi, comprimento de uma circunferência, superfície de um círculo, entre outros)" é condizente com as ações descritas no plano de aula? Quais os argumentos do grupo para manter a habilidade EM13MAT307? Entre outras.

De modo geral, a etapa 2 explicitou dois pontos de tensão: o primeiro refere-se à abordagem didática adotada, que oscilava entre a intenção pelo ensino exploratório e sua real efetivação. Desde o ciclo presencial, o ensino exploratório tem sido estudado e discutido como possibilidade para a prática docente dos estagiários. Todavia, as dificuldades impostas pelo ERE (distribuição dos estudantes em pequenos grupos, baixa participação nas aulas síncronas, baixa qualidade de conexão de internet dos estudantes, entre outros) fez com que os grupos refletissem sobre o quanto o planejamento e a simulação deveriam ser minuciosos para que eles tivessem segurança para desenvolver a aula.

Pedimos à professora supervisora que passasse aos alunos uma mensagem nossa, solicitando os materiais que iríamos utilizar na aula e começamos a 


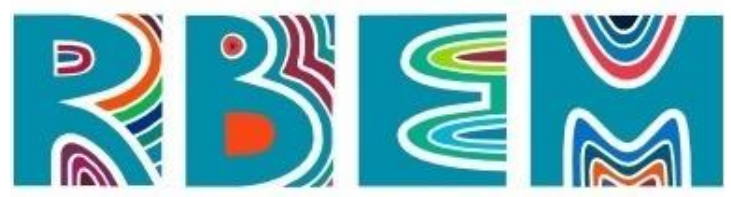

REVISTA BAIANA DE EDUCAÇÃO MATEMÁTICA

nos planejar para executar a atividade de forma mais expositiva caso os alunos não participassem (Estagiário, Grupo 1).

Nesse interim, notamos que a abordagem usual, centrada na explicação do professor com o apoio de slides, seguida de aplicação de exercícios era muito cômoda e menos arriscada para alguns deles. Tudo isso revelava-nos que o Ensino exploratório ainda era estranho para eles, especialmente, pelo fato de eles não o vivenciarem no cotidiano de seu curso de formação. Ademais, os estagiários traziam ao debate lembranças das práticas profissionais dos professores que tiveram na educação básica, em sua maioria, centradas no professor, mostrando a força dessas experiências na constituição do futuro professor.

O segundo ponto de tensão que identificamos, por sua vez, diz respeito às dificuldades de leitura e escrita apresentadas pelos estagiários. A ausência de tópicos curriculares na formação inicial que promovam o desenvolvimento de habilidades de leitura e escrita impuseram desafios à realização do ECSM. Nesta etapa, a dificuldade dos estagiários em ler artigos científicos da área de Ensino dificultava o acesso às orientações, sugestões, resultados de pesquisas e o contato com experiências de outros pesquisadores. Isso foi minimizado por meio da leitura de alguns produtos educacionais provenientes de mestrados profissionais em Educação Matemática ou Ensino de Ciências, que apresentavam os resultados das pesquisas em linguagem mais acessíveis a eles. Entendemos que é necessário avaliar o lugar que a leitura e a escrita ocupam na formação inicial do professor de matemática e os modos como as linguagens materna e matemática são exploradas nas diferentes disciplinas que o compõem. Igualmente, se faz urgente problematizar que a linguagem científica, adotada na literatura em Educação Matemática, pode estar muito distante do professor e do futuro professor, não se constituindo, como desejado, em espaço de socialização de informações e conhecimentos.

\section{Etapa 3: Socialização do planejamento e simulação da aula}

Do mesmo modo que ocorreu no ciclo presencial, o plano de aula de cada grupo foi socializado no grande grupo e a aula simulada. Alteraram-se os recursos, sendo a socialização feita no Drive e a simulação no Zoom. Nessa ocasião, um membro do grupo assumia o papel de professor regente e os demais o papel de observadores, enquanto os colegas dos outros grupos simulavam ações típicas de alunos da escola. Encerrada a simulação, os observadores 


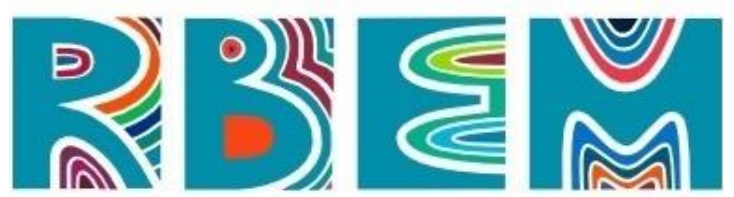

REVISTA BAIANA DE EDUCAÇÃO MATEMÁTICA

expunham suas percepções e considerações sobre a aula ministrada, bem como os demais colegas de disciplina e professoras orientadoras. $\mathrm{O}$ momento da simulação foi usado como testagem de todos os recursos presentes no planejamento, dando destaque aos modos de acesso à internet e à necessidade de instalação, ou não, de conexão com a internet.

A preocupação com a participação dos estudantes se fez presente em todas as simulações de aulas, em especial, pelo fato de a abordagem didática escolhida por alguns requerer o envolvimento dos estudantes, com respostas ao longo da aula via chat ou oralmente. Alinhada a essa preocupação, muitos questionaram a distribuição do tempo de aula no plano, o que se mostrou difícil no ciclo presencial - estimar a duração de cada parte do planejamento - e se mostrou dificílimo no ciclo on-line. Para tanto, decidiu-se, coletivamente, designar a um dos observadores o papel de auxiliar do professor regente no chat. Esse membro estimularia a participação, reuniria as respostas e falaria em voz alta para que o professor regente interagisse com os estudantes. Essa solução agradou a todos pela dificuldade, já observada por eles, de a professora supervisora observar o chat ao longo da aula.

À medida que a aula era simulada, o plano de aula de cada grupo era observado em minúcias, contrastando a escrita do plano e a aula - gerando, por vezes, incompreensões. Por min outro lado, a escrita compreensível do plano fornecia aos estagiários o entendimento de que planejar era um trabalho altamente qualificado que demandava conhecimento especializado do conteúdo matemático e do conteúdo didático-pedagógico. Essas compreensões tencionavam o debate ao contrapor as visões da docência como vocação e como dom, que permeavam o grande grupo. Logo, evidenciou-se a dificuldade dos grupos em antecipar as dúvidas dos estudantes e, especialmente, indicar intervenções a partir delas; o entendimento de que a prática docente deveria ser orientada por objetivos, por intencionalidade e a necessidade de ampliação do conhecimento dos estagiários sobre os tópicos curriculares e sobre estudos que discutiam seu ensino e aprendizagem. Muitas outras sugestões foram apresentadas, ao longo das discussões, quanto à escrita, à tarefa matemática, quanto ao uso dos recursos, entre outros, o que confirmava o valor da simulação da aula e dos debates decorrentes dela para o aprimoramento do plano e para o conhecimento por parte dos futuros professores da aula e suas necessidades. 


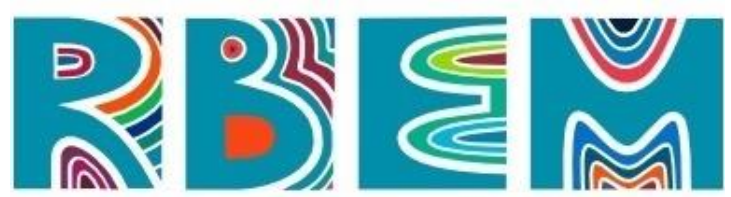

REVISTA BAIANA DE EDUCAÇÃO MATEMÁTICA

Estamos aprendendo juntos com a socialização e plenárias a partir do que os grupos estão trazendo; que a dificuldade de comunicação e interação na realidade do ensino remoto tem sido recorrente; que uma média de 50 alunos em uma aula remota é boa; e que no presencial também tem quem não fala, logo, não podemos afirmar que essa interação não ocorre apenas no remoto. E que fica pergunta: como vamos saber se aqueles que não interagem pelo o chat ou microfone não estão prestando atenção na aula e/ou aprendendo? (Estagiário, Grupo 3).

Uma das vantagens de socializar o planejamento e simular a aula na plataforma Zoom foi garantir o registro completo da etapa (chat, gravação em áudio e vídeo), tendo ainda a possibilidade de separar áudio de imagem, caso fosse necessário. Todas as gravações foram disponibilizadas no Drive, o que favoreceu a retomada da aula simulada pelos grupos e pelo grande grupo, possibilitando que a aula fosse revisitada várias vezes. Alguns estagiários preferiam ouvir somente o áudio com as sugestões e os debates como um podcast, mostrando o quanto a ampliação do registro foi importante para o desenvolvimento do LS on-line.

Desse modo, foi possível perceber que as aulas simuladas constituíram-se em videoaulas que compuseram um repositório no Drive que poderá ser utilizado em ciclos futuros de $L S$ e/ou em outras disciplinas da licenciatura, de acordo com as recomendações para a ética na pesquisa. Entretanto, ao mesmo tempo em que as gravações são registros importantes das ações, elas, também, demandam espaços de armazenamento físicos ou virtuais, impondo ao desenvolvimento do ECSM em processo de $L S$ o apoio institucional ou financiamento para que todo o material gravado seja preservado, transcrito, organizado etc.

Em resumo, observamos, nesta etapa, o quanto os futuros professores aprimoraram suas habilidades ao ensinar e ouvir dos colegas devolutivas sobre a percepção deles na condição de estudantes. Aspectos como: chamar a atenção dos estudantes durante a aula, usar o tempo de forma eficiente; manter a interação dos estudantes; envolver ativamente os estudantes e apoiá-los com apresentações de informações de forma clara e objetiva foram experienciados por eles ao longo das aulas. No entanto, estávamos cientes de que as simulações eram limitadas quanto ao fornecimento das reais condições de acompanhamento das aulas na situação real de aula junto aos estudantes do ensino médio. Estes entendimentos assemelham-se aos construídos por Incikabi e Kacar (2017) e demarcam a necessidade de contrapor as observações empreendidas nesta etapa às efetivadas na etapa 6 . 


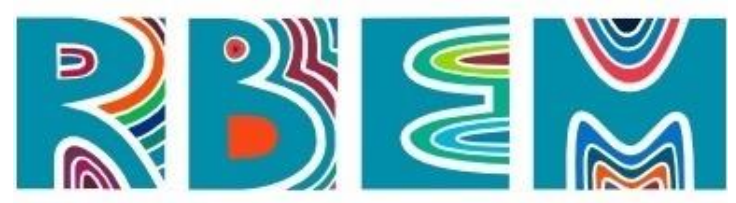

REVISTA BAIANA DE EDUCAÇÃO MATEMÁtica

\section{Etapa 4: Desenvolvimento e observação da aula}

Todos os grupos desenvolveram as aulas síncronas no Google Meet e assíncrona no Google Classrrom. As aulas tiveram duração de 45 minutos cada. O desenvolvimento da aula trouxe a todos os grupos compreensões sobre a gestão da aula, do conteúdo e da participação dos estudantes. Igualmente, possibilitou importantes compreensões sobre o ensino exploratório.

Como imaginamos, poucos alunos levaram os materiais solicitados e nenhum quis mostrar seu objeto pela câmera, mas estávamos preparados para isso e mostramos quatro objetos: um brinco de argola, um anel e duas tampas e começamos a fazer os questionamentos presentes no plano de aula, de forma que os alunos pudessem comparar os objetos e desenvolver os conceitos de círculo e circunferência (GRUPO 1).

Foi utilizada uma mesa digitalizadora no terceiro momento que foi de grande ajuda e deixou a aula muito mais clara e dinâmica. A turma foi muito participativa e isso realmente surpreendeu o grupo positivamente, pois uma das maiores preocupações com a aula era a falta de participação da turma (GRUPO 1).

Um dos pontos mais importantes na aula foi o uso do tempo. Quando planejado, o grupo imaginou que cada ação levaria determinado tempo para ser concluída, no entanto, na hora da apresentação sofremos no final da aula. Faltou tempo e o grupo se viu obrigado a acelerar o final. Tal ação dificulta o entendimento dos estudantes que têm mais dificuldades e assim não conseguimos atingir a todos como gostaríamos (Estagiário, Grupo 2).

Os estagiários aprenderam que a aula exploratória promove a socialização de resoluções, de entendimentos conceituais e precisa de mais tempo para ser realizada. Aprenderam que "destinar mais tempo" não deve ser considerado empecilho visto o valor da aula para o desenvolvimento do pensamento matemático. Aprenderam, também, que, na aula exploratória, as dúvidas dos estudantes são esclarecidas ao longo da aula, fomentando, inclusive, que novas dúvidas e entendimentos sejam verbalizados.

Outros aspectos observados nas aulas da professora supervisora também se fizeram presentes no momento da regência dos estagiários. Problemas quanto à participação foram constantes entre os estudantes de dependência, mostrando que manter o estudante frequentando o ERE foi altamente complexo, em especial, os em situação de dificuldade de aprendizagem ou repetentes. 


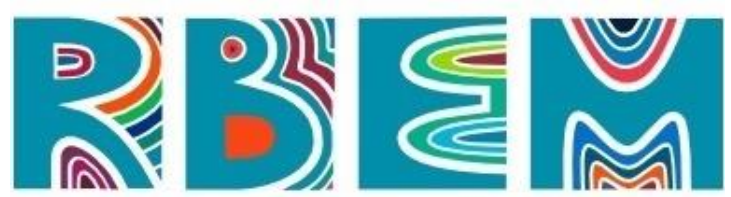

REVISTA BAIANA DE EDUCAÇÃO MATEMÁTICA

\begin{abstract}
A expectativa era que aproximadamente 10 alunos estivessem presentes, contudo, até às $19 \mathrm{~h} 10 \mathrm{~min}$ apenas um ingressou. O grupo, para evitar não ultrapassar o limite de tempo da aula, iniciou as dinâmicas com esse aluno. Este participou, por meio do chat, do preenchimento das duas primeiras colunas da $1^{a}$ tabela, quando sua conexão caiu e ele não conseguiu mais acessar a reunião. Então, um dos integrantes sugeriu que o restante da aula fosse feito pelo próprio grupo e gravada, para uma posterior divulgação no Google Classroom (GRUPO 4).
\end{abstract}

Os estagiários compreenderam que, apesar dos esforços da equipe gestora da escola em telefonar, promover o retorno às aulas, imprimir o material didático, buscar a doação de computadores, entre outros aspectos, as limitações financeiras, tecnológicas e sociais definiram quem continuaria frequentando as aulas ERE na pandemia ante a necessidade de trabalhar para garantir a subsistência.

\title{
Etapa 5: Análise crítica da aula desenvolvida na escola pelos futuros professores e professor (a) supervisor (a) (Plenária 2)
}

Diferentemente do ciclo presencial, em que essa etapa foi realizada em uma sala de aula, na escola, com gravação em áudio, a análise crítica nesta etapa foi realizada no Zoom, momento no qual os estagiários e a professora regente se reuniram para análise crítica e melhorias no planejamento, independentemente de ele ser replicado em outra turma ou não. Os estagiários tiveram a oportunidade de falar como percebiam suas conquistas e dificuldades ante o planejamento construído, como se percebiam ou não professores.

A preocupação dos estagiários quanto à participação dos estudantes foi, sem dúvida, um primeiro item da análise. Ao acompanharem as aulas da professora supervisora, eles constataram que a baixa participação era um grave problema que eles buscaram resolver no planejamento, atentando-se a uma melhor delimitação do tempo, aos recursos tecnológicos adotados, aos modos de buscar a interação dos estudantes. Para estagiários, professoras orientadoras e supervisora, sem a participação efetiva dos discentes, o desenvolvimento da aula e a aprendizagem dos alunos ficam comprometidos.

Ao debaterem o item, foi consensual que o planejamento estimulou a participação dos estudantes em vários momentos da aula, ao convidá-los a expor suas compreensões sobre os 


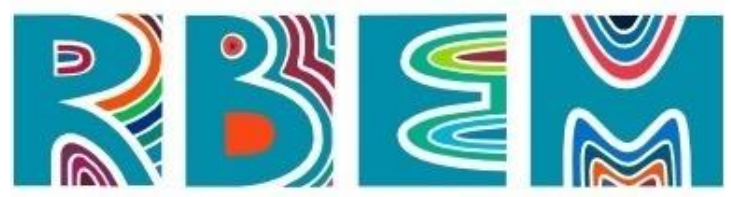

REVISTA BAIANA DE EDUCAÇĀO MATEMÁTICA

conteúdos, as resoluções por meio do chat, Jamboard de forms, Kahoot, entre outros. A inclusão de tais recursos pelos estagiários e a aceitação positiva deles pelos estudantes fez com que a professora supervisora passasse a utilizá-los em suas aulas, sendo a principal contribuição dos estagiários ao trabalho da professora supervisora. Por outro lado, ela contribuiu, sobremaneira, para o trabalho dos estagiários com sua experiência quanto à gestão do tempo, à seleção de tarefas matemáticas e ao tratamento delas junto aos estudantes. Desse modo, ampliou-se o entendimento entre eles do quanto a interação entre professor experiente e futuro professor é produtiva e geradora de aprendizagens não apenas para os futuros professores.

O modo como o chat foi explorado pelos estagiários abriu espaço para novas possibilidades de participação dos estudantes e isso foi possível pela presença de um estagiário nesse espaço. O fato de trabalhar em grupo, em todas as etapas do LS on-line, permitiu que as ações de professor regente e professor observador fossem bem distribuídas entre eles, ampliando a mediação, o suporte e a presença do professor junto às demandas dos estudantes. A presença do grupo deu segurança e acalmou a todos nos momentos de insegurança, medos e receios típicos dessa fase da formação. Tudo isso foi verbalizado pela professora supervisora e demarcou a importância de se construir núcleos de colaboração no ciclo de $L S$ (o grande grupo, o grupo, professoras orientadoras, supervisora e estudantes).

\section{Etapa 6: Análise crítica da aula desenvolvida na escola pelos futuros professores e professor (a) orientadora (a) (Plenária 3)}

Diferentemente do ciclo presencial, em que a análise crítica foi realizada em sala de aula, com gravação por meio de câmara com tripé ao fundo, esta etapa foi realizada no Zoom e contou também com a participação de todos os estagiários e da professora orientadora, considerando, na promoção dos diálogos, o planejamento, a aula e a plenária 2. A realização no Zoom desafiou à professora orientadora quanto a equilibrar os tempos de fala, as complementações de falas entre os membros do mesmo grupo e/ou as concordâncias e divergências entre os grupos. O planejamento foi contrastado com a realidade da aula desenvolvida e, por vezes, com destaques para as alegrias e as frustrações deste momento. Do mesmo modo, a necessidade de flexibilizar o planejamento, atentando-se para as diferentes 


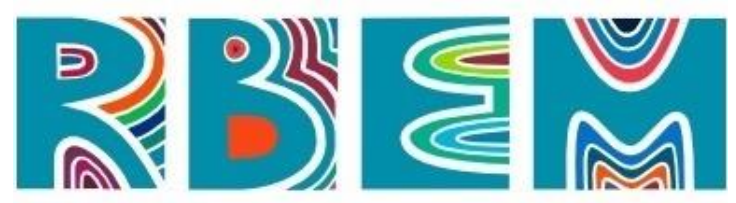

REVISTA BAIANA DE EDUCAÇÃO MATEMÁTICA

realidades escolares, foi consensual, definindo o entendimento de uma ação da prática profissional.

Na segunda aula tinha poucos alunos. Somente duas e elas não participaram. O que gerou uma frustação, pois a estagiária desenvolveu a aula sem alunos. Somente com a presença da professora regente e os demais colegas estagiários do grupo. Não houve interação. O tempo sobrou.

O grupo relatou que com a ausência de alunos, na primeira aula, fizeram uma simulação de outra forma para deixar gravado para os alunos e explicando cada passo.

Os grupos foram unânimes em valorar o suporte fornecido pela professora supervisora, ao longo das aulas, com sua presença nas aulas síncronas. Suas devolutivas pontuais, quando necessário, e as discussões da Plenária 1 mostraram a eles a seriedade de seu trabalho e seu empenho em contribuir com a formação dos estagiários. Ademais, a convivência com ela confirmou o "inacabamento" dessa formação, tendo em vista que ela, às vésperas de se aposentar na SEEDF, estava em sala, em cursos, com os estagiários, com as professoras orientadoras, ávida por novos conhecimentos, por aprender como desenvolver a aula de matemática no ERE. A professora supervisora exerceu influência positiva junto aos estagiários, uma vez que se mostrou curiosa, estudiosa, ativa, disposta a errar e a acertar quanto a conhecer e utilizar, em suas aulas, recursos tecnológicos diversos. "As dificuldades foram muitas, mas com elas também vieram aprendizados, foi necessário se reinventar nesse período" (Estagiário, Grupo 4).

Os desafios do ERE foram debatidos, fortemente, vinculados à díade participação aprendizagem matemática, provocando nos estagiários a observação das chances de aprendizagem dos estudantes atendidos por eles ao longo do estágio.

Como vamos saber se aqueles que não interagem pelo chat ou microfone não estão prestando atenção na aula e/ou aprendendo? (Grupo 2)

O ensino remoto retirou a possibilidade de uma educação "olho-no-olho", onde o professor consegue perceber pelos sinais corporais do aluno se o mesmo está ou não entendendo o conteúdo. (Grupo 1)

O grande grupo avaliou positivamente as vantagens da docência compartilhada. Ter o professor regente, os observadores, o professor no chat mostrou a todos o valor da parceria na ação docente. Sabemos das limitações e das dificuldades para que tal prática seja efetivada 


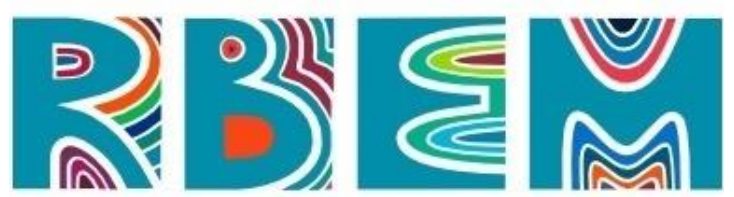

REVISTA BAIANA DE EDUCAÇÃO MATEMÁTICA

nas condições, por vezes, limitantes em quantitativo de professores da rede pública, mas percebemos, também, que isso já é realidade em escolas voltadas às classes mais favorecidas economicamente. No entanto, entendemos que a inovação, construída no ECSM, pode ser motivadora para que novas experiências sejam elaboradas em outros formatos, dinâmicas, possibilitando a partilha entre os docentes, de modo que isso possa acontecer em mais disciplinas da licenciatura em matemática, rompendo as divisões clássicas entre as áreas, entre as disciplinas, que compõem a formação do futuro professor.

Outro aspecto importante da profissão e que notamos bem ao longo desse semestre é que a docência só ocorre em conjunto, na sala de aula com a participação dos alunos, na escola como um todo, o trabalho é em conjunto com os outros professores, coordenadores, orientadores, diretores, enfim todos os profissionais da escola e certamente com as famílias dos estudantes também, criando assim, de fato, uma comunidade escolar com vários profissionais trabalhando conjuntos.

A regência foi a mais trabalhosa e que nos trouxe mais conhecimentos profissionais. A dificuldade da realização de um plano de aula (De acordo com a metodologia Lesson Study) nos faz acreditar que precisamos cada vez mais praticar essa elaboração, pois com isso poderemos adquirir mais aperfeiçoamento e conhecimentos para esse desenvolvimento. (Grupo 2)

Uma característica do $L S$ japonês foi debatida na plenária em associação ao modo como o ECSM em processo de $L S$ tem sido desenvolvido em nossa instituição. O grande grupo percebeu que temos criado oportunidades para que professores experientes e futuros professores interajam ao longo de todas as etapas, ampliando igualmente a presença do professor supervisor em etapas que, tradicionalmente, eram realizadas somente por professores da universidade.

\section{Etapa 7: Sistematização da experiência}

A sistematização da experiência aconteceu por meio da escrita do Relatório Final, que promoveu a reflexão individual e coletiva entre os estagiários. Nesse momento, eles vivenciaram os desafios da escrita em uma cultura formativa que pouco promove a escrita reflexiva. Aos poucos, eles se permitiram escrever sobre o vivido, sobre os sentimentos que permeavam a experiência do ECSM, compreendendo-a e compreendendo-se por meio da 


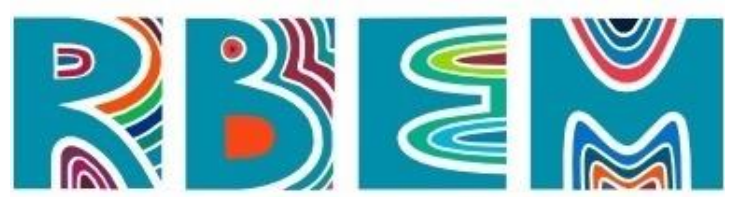

REVISTA BAIANA DE EDUCAÇÃo MATEMÁTICA

escrita. A escrita do relatório final (Quadro 4) foi precedida de pequenas escritas, ao longo do semestre, chamadas de Relatório de aula, no qual cada estagiário relatava o encontro síncrono e suas percepções sobre ele.

Quadro 4: Relato do Estagiário M referente ao encontro 4 síncrono

\section{RELATO DA AULA}

Em nossa quarta aula, tivemos a realização de uma atividade em grupo antes da aula e, logo após, tivemos a apresentação do último grupo sobre as Orientações para avaliação remota e o Guia de avaliação para o novo ensino médio. Em relação à primeira atividade, esta foi dividida em duas etapas. A primeira consistia em resolver um questionário em grupo. A segunda consistia na correção pelo nosso grupo do questionário respondido por outro grupo.

A expectativa quanto à primeira etapa era uma revisão do conteúdo referente às apresentações anteriores. No entanto, esta foi bem diferente, na qual deveríamos responder algumas questões envolvendo cálculos e fórmulas. Apesar de estranhar o formato da atividade no começo, ao resolvê-la me senti mais confortável.

Na segunda etapa, foi interessante a discussão conjunta do grupo para corrigir a tarefa, pois não é um trabalho simples quando se lida com questões não objetivas e não possuímos um gabarito. Na apresentação, foi interessante ver o grupo apresentar os novos parâmetros de avaliação e as novas orientações para elaborá-las, porém entendemos que a implementação dos mesmos se mostrará um obstáculo, pois as escolas e os professores ainda não estão preparados para seguir esses novos modelos. No caso das escolas, a justificativa seria a desarticulação curricular, enquanto dos professores a própria formação desses quanto aos métodos avaliativos.

Fonte: Relatório de Pesquisa.

Desse modo, entendemos que o "[...] registro escrito, tanto das vivências pessoais como das práticas profissionais, é essencial para que cada um adquira uma maior consciência de seu trabalho e da sua identidade como professor" (NÓVOA, 2009, p. 182). Nele, dividimos coletivamente (compartilhado no Drive) sensações, emoções, dúvidas, medos e conquistas que permitiram a aproximação dos estagiários da futura prática profissional. Os trechos, a seguir, revelam algumas destas reflexões, expressas nos relatórios, e marcam o modo como conseguiram significar o trabalho desenvolvido no ESCM.

Em geral, acreditamos que o material que criamos é completo e poderia ser adaptado muito bem para a aplicação de forma presencial, realizando apenas algumas alterações, tais como: solicitar ao professor que leve o barbante e demais materiais que os alunos possam não ter em casa, para que assim esteja melhor preparado caso algum aluno não os tenha disponível; fazer mudanças no plano, de maneira que, ao invés de mostrar o vídeo (presente no plano de aula), possa deixar que o estudante construa a área do círculo por meio de "triângulos" cada vez menores, como realizado na apresentação. (Relatório Final, Grupo 1)

O Lesson Study nos deu uma opção de caminho para melhorarmos sempre, a aprender a compartilhar e ver as ações em sala de aula por outros ângulos de vista, a aceitar opiniões e que somente através do diálogo e troca de ideais que podemos aperfeiçoar os métodos para cada matéria a ser ensinada, levando em conta vários aspectos de cada turma e alunos. (Relatório Final, Grupo 4) 


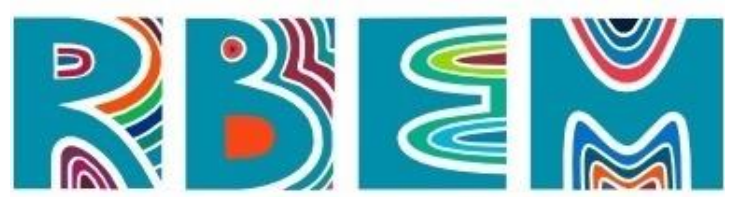

REVISTA BAIANA DE EDUCAÇÃO MATEMÁTICA

Tivemos que primeiramente aprender conceitos novos, tivemos que entender o que era o ensino remoto para assim conseguirmos executá-lo de forma plausível, tivemos várias dificuldades acerca de como produzir um plano de aula onde não teríamos contato físico com nenhum aluno, não poderíamos saber como o aluno está fazendo a sua atividade para assim entender a sua dificuldade e poder corrigi-lo ou até o fazer questionar até o ponto dele próprio entender o erro do mesmo. (Relatório Final, Grupo 3)

A estrutura do relatório final proporcionou que os estagiários socializassem suas reflexões a respeito da elaboração e organização dos materiais e arquivos, que abordaram tanto o domínio de conhecimentos teóricos quanto dos instrumentos práticos. Tais instrumentos foram imprescindíveis à execução de suas funções e também oportunizaram o desenvolvimento profissional, dos conhecimentos teóricos e didáticos, além de favorecer possíveis adaptações, por meio de diversos espaços educacionais.

\section{Alguns entendimentos}

Desenvolver o ECSM em processo de $L S$ on-line permitiu compreender as adaptações, as inovações e os desafios necessários a sua realização, ao mesmo tempo em que possibilitou aos participantes importantes compreensões sobre a escola, o ensino, a aprendizagem e profissão docente.

O desafio inicial para o desenvolvimento de $L S$ on-line foi, sem dúvida, a qualidade da conexão de internet. Muitos estagiários residiam em áreas distantes do centro urbano, muitos estudantes do ensino médio residiam em áreas rurais, o que gerou problemas de acesso e de manutenção da conexão, ocasionando cortes e interrupções nas falas, “caídas”, entre outros contratempos. Isso nos mostrou que o acesso à internet, no Brasil, ainda, é fator de exclusão, de diferenciação no acesso à educação, principalmente na escola pública. Essa dificuldade foi sanada, em parte, pelo acesso às gravações dos encontros, aulas e discussões.

A gravação de todas as etapas trouxe inovação se comparada ao ciclo presencial, no qual a gravação foi trabalhosa e dispendiosa pelo fato de ser realizada em salas de aula da universidade e na escola, exigindo equipamentos adequados e recursos humanos. Todavia, esta possibilidade trouxe consigo o desafio do armazenamento e do tratamento das gravações, demandando dos pesquisadores e das instituições a criação de alternativas técnicas e éticas. 


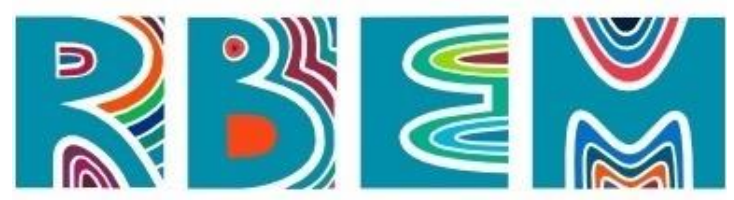

REVISTA BAIANA DE EDUCAÇÃO MATEMÁTICA

Todos os participantes conheceram como uma escola da rede pública do DF tem lidado com o ERE, como buscaram ampliar a presença dos estudantes nas aulas síncronas e assíncronas e sua efetiva participação nesses espaços. Compreenderam, igualmente, que a condição social dos estudantes influencia diretamente no acesso e na permanência nas aulas on-line, do mesmo modo que os recursos tecnológicos na participação nas aulas. A baixíssima participação dos estudantes nas aulas de matemática merece estudos específicos. Indagamonos, por exemplo, se nos demais componentes curriculares essa participação também foi baixa? Qual é a relação entre ausência nas aulas síncronas e evasão escolar? Qual é o impacto do componente curricular de matemática na evasão escolar no ensino médio no ano de 2020 ?

Tudo isso exige questionamentos quanto à abordagem didática adotada pelos professores. É preciso refletir se a adoção pelos professores de práticas usuais em situação de ensino remoto, nas quais o estudante continua reproduzindo, recebendo, o conhecimento "transmitido pelo professor", se tornou insustentável para os estudantes. Sabemos que a atualidade trouxe a urgência de os professores desenvolverem pensamentos e habilidades computacionais, recorrerem a recursos tecnológicos, a plataformas de videoconferência, plataformas de comunicação, plataformas de atividade e softwares em geral, mas tudo isso só será útil se vier atrelado à transformação das abordagens didáticas, em especial, de modo a ampliar o protagonismo dos estudantes e o diálogo entre eles.

Os núcleos de colaboração (grande grupo, grupo, professoras orientadorassupervisora) criaram uma rede de apoio mútuo que favoreceu e facilitou o trabalho ao longo das etapas. O planejamento de aulas, em aproximação ao ensino exploratório, ampliou as possibilidades de fala dos estudantes durante as aulas. Tudo isso diminuiu a distância causada pela não presencialidade do LS on-line. O uso eficaz dos aparatos tecnológicos pelos estagiários mostrou que eles - enquanto nativos digitais - relacionam-se com a tecnologia com familiaridade, curiosidade e muito respeito às necessidades dos estudantes.

O ciclo de LS on-line ampliou a utilização do Drive para o compartilhamento de materiais e da escrita coletiva, dando a todos mais responsabilidades frente à produção do colega e à sua produção. As horas desenvolvidas de modo assíncrono, entre a professora orientadora e os estagiários, promoveram, também, o estudo individualizado e contribuíram para que os estagiários desenvolvessem mais autonomia, criticidade e inovação no trabalho realizado. A ampla exploração do chat, designando um professor para aquele espaço, foi 


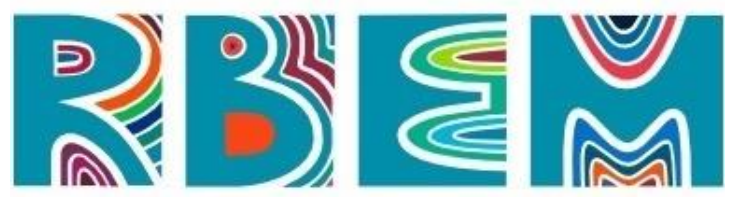

REVISTA BAIANA DE EDUCAÇÃO MATEMÁTICA

muito importante, pois tornou possível aprimorar os pontos de vista em diferentes enfoques, como o gerenciamento da aula remota, o uso de recursos e materiais, o acolhimento, a aprendizagem dos alunos e o ensino de matemática em diferentes contextos.

De modo geral, compreendemos que o desenvolvimento do ECMS em processo de LS on-line pode ser um importante espaço formativo e de desenvolvimento profissional para o futuro sem pandemias. Assim, temos ciência de que, ao retornarmos para o formato presencial, estaremos acrescidos das compreensões que foram construídas e estamos certos de que elas podem reconstruir os modos como desenvolvemos o ECSM em nossa instituição. Do mesmo modo, entendemos que essa experiência ajuda-nos no reconhecimento do trabalho dos professores, na necessidade de ampliar as discussões e as experiências formativas on-line, seja na educação básica ou no ensino superior, visto que há a necessidade de promover a inclusão digital entre estudantes e professores. Além disso, ajuda-nos a valorizar a escola, a presencialidade e a buscar experiências educacionais e formativas que transitem entre o presencial e o on-line.

\section{Referências}

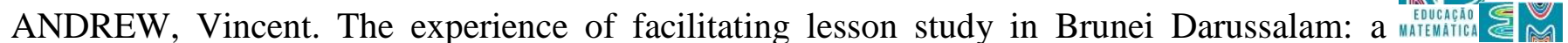
practice insight working paper. CollectivED Working Paper, Carnegie School of Education, v. 10, p. 40-44, Leeds Beckett University, 2020. Disponível em: https://www.leedsbeckett.ac.uk/-/media/files/research/collectived/collectived-issue-10.pdf.

Acesso em: 11 nov. 2021.

BARBOSA, Cirléia Pereira; LOPES, Celi Espasandin. O estágio supervisionado na Licenciatura em Matemática: um panorama das pesquisas brasileiras. In: SEMINÁRIO INTERNACIONAL DE EDUCAÇÃO MATEMÁTICA, 7 - SIPEM. 2018, Foz do Iguaçu, Paraná, Anais [...]. Foz do Iguaçu, 2018, p. 1-12.

BARBOSA, Cirléia Pereira; LOPES, Celi Espasandin. Uma análise da produção acadêmica brasileira sobre o Estágio Curricular Supervisionado nos cursos de Licenciatura em Matemática. Revista de Educação Matemática, Guarulhos/SP, v. 18, p. e021014, 26 mar. 2021.

BALDIN, Yuriko Yamamoto. O significado da introdução da Metodologia Japonesa de Lesson study nos Cursos de Capacitação de Professores de Matemática no Brasil. In: ENCONTRO ANUAL DA SBPN E SIMPÓSIO BRASIL-JAPÃO, 18. 2009, São Paulo, SP. Anais [...]. São Paulo, SP, SBPN, 2009.

BALDIN, Yuriko Yamamoto; FELIX, Thiago Francisco. A pesquisa de aula (Lesson study) como ferramenta de melhoria da prática na sala de aula. In: CONFERÊNCIA 


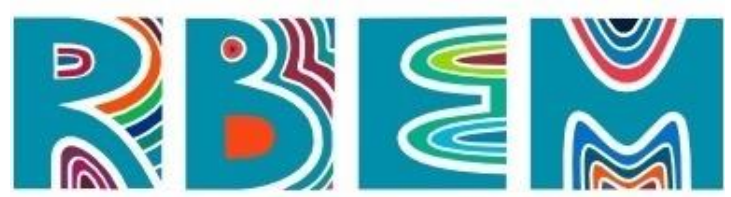

REVISTA BAIANA DE EDUCAÇÃO MATEMÁTICA

INTERAMERICANA DE EDUCAÇÃO MATEMÁTICA, 13. CIAEM, 2011, Recife. Anais [...]. Recife, Brasil, 2011.

BAPTISTA, M. et al. O Lesson Study como estratégia de formação de professores a partir da prática profissional. In: SANTOS, Leonor et al. (Eds.). Investigação em Educação Matemática 2012: práticas de ensino da Matemática. 2012. p. 494 - 505.

BEZERRA, Renata Camacho. Aprendizagens e desenvolvimento profissional de professores que ensinam Matemática nos anos iniciais do Ensino Fundamental no contexto da Lesson Study. 2017. 210 f. Tese (Doutorado em Educação)- Universidade Estadual Paulista, Presidente Prudente, SP, 2017.

CRECCI, Vanessa Moreira; FIORENTINI, Dario. Desenvolvimento Profissional em comunidades de aprendizagem docente. Educação em Revista, Belo Horizonte, v. 34, p. 1-18, 2018.

CRECCI, Vanessa Moreira; PAULA, Andrey de; FIORENTINI, Dario. Desenvolvimento profissional de uma professora dos anos iniciais que participa de um Lesson Study Híbrido. Educere et Educare, [s. 1.], v. 14, p. 1-21, 2019.

CRUZ, Maria Aparecida Silva; BITTAR, Marilena. O futuro professor de matemática no estágio supervisionado: uma experiência de formação compartilhada no contexto da Lesson Study. Educação Matemática em Revista, Porto Alegre, v. 2, p. 123-133, 2019.

CRISTOVÃO, Eliane Matesco; FIORENTINI, Dario. A investigação narrativa no estudo da aprendizagem de professores de matemática em espaços colaborativos híbridos universidadeescola. Sisyphus - Journal of Education, [s. 1.], v. 9, p. 34-60, 2021.

CURI, Edda. Reflexões sobre um Projeto de Pesquisa que envolve grupos colaborativos e a metodologia Lesson Study. In: CURI, Edda; NASCIMENTO, Julia de Cassia Pereira; VECE, Janaina Pinheiro. (Org.). Grupos Colaborativos e Lesson Study: contribuições para a melhoria do ensino de Matemática e desenvolvimento profissional de professores. São Paulo: Alexa Cultural, 2018, p. 17-33.

DUDLEY, Peter. Lesson Study: professional learning for our time. Abingdon: Routledge, 2015.

FIORENTINI, Dario; NACARATO, Adair Mendes; FERREIRA, Ana Cristina; LOPES, Celi Espasadim; FREITAS, Maria Teresa Meneses; MISKULIN, Rosana Giaretta Sguerra. Formação de professores que ensinam matemática: um balanço de 25 anos da pesquisa brasileira. Educação em Revista, Belo Horizonte, n. 36, p. 137-160, 2002.

FIORENTINI, Dario; OLIVEIRA, Ana Teresa de Carvalho Correa de. O lugar das matemáticas na Licenciatura em Matemática: que matemáticas e que práticas formativas? Bolema [online], v. 27, n. 47, p. 917-938, 2013. 


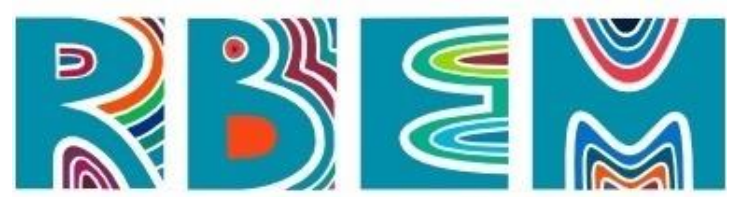

REVISTA BAIANA DE EDUCAÇÃO MATEMÁTICA

FIORENTINI, Dario; PASSOS, Carmen Lúcia Brancaglion; LIMA, Rosana Catarina Rodrigues de. (Org.) Mapeamento da pesquisa acadêmica brasileira sobre o professor que ensina matemática: período 2001 - 2012. Campinas, SP: FE/UNICAMP, 2016.

FIORENTINI, D.; RIBEIRO, C.M.; CRECCI, V.M.; LOSANO, A. L.; VIDAL, C.P.; FERRASSO, T. Estudo de uma experiência de Lesson Study Híbrido na formação docente em matemática: contribuições de/para uma didática em ação. In: ENCONTRO NACIONAL DE DIDÁTICA E PRÁTICA DE ENSINO, 19. 2018, Salvador. Anais [...]. Salvador, p. 1-38. 2018.

GOMES, M. L. M. Os 80 anos do primeiro curso de Matemática brasileiro: sentidos possíveis de uma comemoração acerca da formação de professores no Brasil. Bolema, Rio Claro, v. 30, n.55, p. 424-438, 2016.

GRUPO DE ESTUDO E PESQUISA SOBRE FORMAÇÃO DE PROFESSORES DE MATEMÁTICA E AS REVISÕES SISTEMÁTICAS - GEPFPM.. In: OLIVEIRA, A. M. P.; ORTIGÃO, M. I. R. (Orgs.). Abordagens Teóricas e Metodológicas nas Pesquisas em Educação Matemática. Brasília: SBEM, 2018. p. 234-254.

HUANG, Rongjin; TAKAHASHI, Akihiko; PONTE, João Pedro da (Org.). Theory and Practice of Lesson Study in Mathematics. Springer International Publishing, 2019.

JÄHRING WANDERLEY, Roger Artur; VEIGA FERREIRA DE SOUZA, Maria Alice. Lesson Study como Processo de Desenvolvimento Profissional de Professores de Matemática sobre o Conceito de Volume. Perspectivas da Educação Matemática, Campo Grande/MS, v. 13, n. 33, p. 1-20, 22 set. 2020.

QUARESMA, Marisa; PONTE, João Pedro da; BAPTISTA, Mônica; MATA-PEREIRA, Joana. O estudo de aula como processo de desenvolvimento profissional. In: SEMINÁRIO DE INVESTIGAÇÃO EM EDUCAÇÃO MATEMÁTICA, 25. 2014, Braga. Anais [...]. Braga: APM, p. 311-325, 2014.

LEWIS, Catherine. How does lesson study improve mathematics instruction? ZDM: Mathematics Educacion, [s. 1.], v. 48, n. 4, p. 571-580, 2016.

LEWIS, Catherine; HURD, Jacqueline. Lesson study step by step: how teacher learning communities improve instruction. Portsmouth: Heinemann, 2011.

LOPES, Anemari Roesler Luersen Vieira; PAIVA, Maria Auxiliadora Vilela; PEREIRA, Patrícia Sandalo; POZEBON, Simone; CEDRO, Wellington Lima. Estágio Curricular Supervisionado nas licenciaturas em Matemática: reflexões sobre as pesquisas brasileiras. Zetétike, Campinas, v. 25, n. 1, p. 75-93, 2017. 


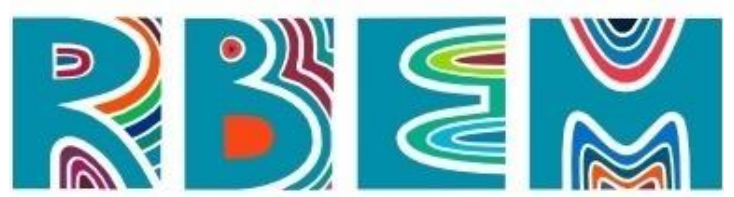

REVISTA BAIANA DE EDUCAÇÃO MATEMÁTICA

LOPES, Celi Espasandin; TRALDI, Armando; FERREIRA Ana Cristina (Org.). O estágio na formação inicial do professor que ensina matemática. Campinas, SP: Mercado de Letras, 2015.

LÜDKE, M. Avaliação Institucional: formação de docentes para o Ensino Fundamental e Médio (As Licenciaturas). Estudos e Debates 19 - Brasília: INEP; Rio de Janeiro: PUC/RJ, 1997, p. 137- 215.

INCIKABI, Lutfi; KACAR, Ahmet Analyzing Prospective Mathematics Teachers' Development of Teaching Practices in Mathematics: A Lesson Study Approach. In: KEENGWE, J.; ONCHWARI, G. (Eds.), Handbook of Research on Learner-Centered Pedagogy in Teacher Education and Professional Development. Hersley, PA: IGI Global, 2017. p. 206-225.

MARTÍNEZ, S.; GUÍÑEZ, F.; ZAMORA, R.; BUSTOS, S.; RODRIGUEZ, B. On the instructional model of a blended learning program for developing mathematical knowledge for teaching", ZDM Mathematics Education, [s. 1.], v. 52, p. 877-891, 2020.

PINA NEVES, Regina da Silva; FIORENTINI, Dario. Aprendizagens de Futuros Professores de Matemática em um Estágio Curricular Supervisionado em Processo de Lesson Study.

Perspectivas da Educação Matemática, [s. 1.], v. 14, n. 34, p. 1-30, 2021.

PINA NEVES, Regina da Silva; FIORENTINI, Dario; SILVA, Janaína Mendes Pereira.

Lesson Study presencial e o Estágio Curricular Supervisionado em Matemática: contribuições à aprendizagem docente. PARADIGMA, 2022 (no prelo).

SOCIEDADE BRASILEIRA DE EDUCAÇÃO MATEMÁTICA - SBEM. A formação do professor de matemática no curso de licenciatura: reflexões produzidas pela comissão paritária SBEM/SBM. Brasília: Sociedade Brasileira de Educação Matemática, Boletim SBEM, n. 21, fevereiro, p. 1-42, 2013.

RICHIT, Adriana; PONTE, João Pedro da; TOMKELSKI, Mauri. Estudos de aula na formação de professores de matemática do ensino médio. Revista Brasileira de Estudos Pedagógicos, Brasília, v. 100, n. 254, p. 54-81, 2019. Doi: http://dx.doi.org/10.24109/21766681.rbep.100i254.3961

SILVA, Aluska Dias Ramos de Macedo. Contribuições da Jugyou Kenkyuu e da engenharia didática para a formação e o desenvolvimento profissional de professores de matemática no âmbito do estágio curricular supervisionado. 2020. 260 f. (Tese de Doutorado)- Universidade Federal de Pernambuco. Recife/PE, 2020.

SOUZA, Maria Alice Veiga Ferreira de; WROBEL, Julia Schaetzle; BALDIN, Yuriko Yamamoto. Lesson Study como Meio para a Formação Inicial e Continuada de Professores de Matemática - Entrevista com Yuriko Yamamoto Baldin. Boletim GEPEM. n. 73 - jul. /dez. 2018. Disponível em: http://doi.editoracubo.com.br/10.4322/gepem.2018.020. Acesso em: 15 fev. 2019. 


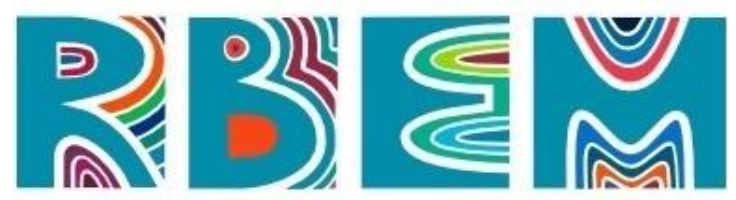

SOUZA, Maria Alice Veiga Ferreira de; WROBEL, Julia Schaetzle; GAIGHER, Vanessa Ribeiro. Planejamentos colaborativos e reflexivos de aulas baseadas em resolução de problemas verbais de matemática. Revista VIDYA, [s. 1.], v. 37, n. 1, p. 51-73, jan./jun., 2017 Santa Maria, 2017.

ZIMMER, Iara. Estágio Curricular Supervisionado na Licenciatura em Matemática: um componente curricular em discussão. 2017. 220 f. Tese (Doutorado em Educação Matemática)- Pontifícia Universidade Católica de São Paulo, 2017.

Artigo submetido em: 30/07/2021

Artigo aceito em: 03/12/2021 